Eur. J. Clin. Chem. Clin. Biochem.

Vol. 30, 1992, pp. 187-191

(C) 1992 Walter de Gruyter \& Co. Berlin $\cdot$ New York

\title{
Effect of Ascorbic Acid on Neutrophil Functions and Hypoxanthine/Xanthine Oxidase-Generated, Oxygen-Derived Radicals
}

\author{
By A. Dwenger ${ }^{1}$, Monika Funck ${ }^{1}$, Britta Lueken ${ }^{1}$, Gertraud Schweitzer ${ }^{1}$, and U. Lehmann ${ }^{2}$ \\ 1 Abteilung für Klinische Biochemie \\ ${ }^{2}$ Unfallchirurgische Klinik \\ Medizinische Hochschule Hannover
}

(Received September 5, 1991/January 14, 1992)

Summary: The effect of ascorbic acid on neutrophil functions was investigated.

The chemiluminescence of isolated neutrophils, stimulated with $\mathrm{N}$-formyl- $L$-methionyl- $L$-leucyl- $L$-phenylalanine, latex, lipopolysaccharide from Escherichia coli, zymosan A, or $4 \beta$-phorbol $12 \beta$-myristate $13 \alpha$-acetate was inhibited up to $99 \%$ by the dose-dependent oxygen radical scavenging activity of $6 \mathrm{mmol} / \mathrm{l}$ ascorbic acid. The chemiluminescence of neutrophils in blood, stimulated with $4 \beta$-phorbol $12 \beta$-myristate $13 \alpha$-acetate, or with zymosan A was inhibited $35 \%$ or $48 \%$, respectively, by $6 \mathrm{mmol} / \mathrm{l}$ ascorbic acid.

Ascorbic acid, up to $6 \mathrm{mmol} / \mathrm{l}$, did not inhibit the release of $\beta$ - $\mathrm{N}$-acetylglucosaminidase and elastase from isolated neutrophils activated by the above stimulatory agents.

During neutrophil/nylon fibre interaction ascorbic acid reduced the oxygen radical production dose-dependently (77\% inhibition of the chemiluminescence response at $6 \mathrm{mmol} / \mathrm{l}$ ascorbic acid), whereas the adherence was unaffected. Hypoxanthine/xanthine oxidase-generated oxygen radicals were scavenged by ascorbic acid in a dose-dependent manner ( $99 \%$ inhibition of the chemiluminescence response at $100 \mu \mathrm{mol} / \mathrm{l}$ ascorbic acid).

From these results, ascorbic acid can highly be recommended for animal experiments and clinical studies in patients with trauma, shock and sepsis and for studies to prevent or reduce reperfusion injuries.

\section{Introduction}

Oxygen-derived free radicals are increasingly recognized as the major cause of mono or multiple organ failure, and for reperfusion injury in different organs $(1-3)$. These radicals are produced extracellularly by

\section{1) Enzymes}

$\beta$-N-acetylglucosaminidase, 2 -acetamido-2-deoxy- $\beta$ - $D$-glucoside acetamido-deoxyglucohydrolase (EC 3.2.1.30) catalase, hydrogen-peroxide:hydrogen-peroxide oxidoreductase (EC 1.11.1.6)

elastase, leukocyte, lysosomal elastase (EC 3.4.21.37)

$L$-gulonolactone oxidase, $L$-gulono- $\gamma$-lactone:oxygen 2-oxidoreductase (EC 1.1.3.8)

superoxide dismutase, superoxide:superoxide oxidoreductase (EC 1.15.1.1)

xanthine oxidase, xanthine:oxygen oxidoreductase (EC 1.2.3.2) activated neutrophils and by the endothelial intracellular route by the hypoxanthine/xanthine oxidase ${ }^{1}$ ) system. Many experimental data show the beneficial effect of an antioxidant treatment to prevent or to minimize oxidant-mediated tissue damage; such antioxidants include allopurinol, oxypurinol, tungsten, superoxide dismutase ${ }^{1}$ ), catalase ${ }^{1}$ ), dimethyl sulphoxide, desferrioxamine, lactoferrin, transferrin, $\mathrm{N}$-acetylcysteine, dimethyl thiourea, dihydrobenzoic acid, glutathione, $\beta$-carotene and $\alpha$-tocopherol. Surprisingly, the naturally occurring non-toxic compound, ascorbic acid with its excellent antioxidative properties has not attracted attention in this context with the recent exception of the evaluation of its role in the modulation of oxidant stress mediated by cigarette smoke-activated phagocytes (4). Furthermore, an- 
other report has described ascorbic acid as the most effective antioxidant in human blood plasma in relation to lipid peroxidation (5), and the authors suggested that ascorbic acid should prove very helpful in the treatment and prevention of diseases and degenerative processes caused by oxidative stress.

Due to an evolutionary defect of the $L$-gulonolactone oxidase gene, which arose about 60 million years ago, man and some other species are unable to biosynthesize ascorbic acid. It has been calculated that the hypothetical endogenous synthesis capacity of a $70 \mathrm{~kg}$ person increases up to $15 \mathrm{~g}$ /day under stress, representing the quantity needed for the array of different protective and host defence functions, but which is never be attained by enteral intake (6). Thus, in extreme oxidative stress situations the infusion of increased amounts of ascorbic acid seems to be necessary and advisable.

Therefore, to substantiate this idea experimentally and to obtain data on the potentially beneficial use of ascorbic acid in organ failure diseases like the adult respiratory distress syndrome (ARDS), we investigated the effect of ascorbic acid on the oxygen radical formation of activated neutrophils and the hypoxanthine/xanthine oxidase system. Furthermore, the influence of ascorbic acid on pathophysiologically important functions of neutrophils, like the lysosomal enzyme release and adherence, was also monitored.

\section{Materials and Methods}

Chemicals and reagents

E. Merck, Darmstadt, Germany: Türk's solution for leukocyte counting; digitonin; test combination PMN Elastase, IMAC; $L(+)$-ascorbic acid.

Pharmacia Fine Chemicals, Sweden: Percoll for density gradient centrifugation.

Boehringer, Mannheim, Germany: luminol; lucigenin; Minimal Essential Medium Dulbecco for chemiluminescence.

Laboratorium Prof. Dr. Berthold, Wildbad, Germany: $3.5 \mathrm{ml}$ polystyrene vials for chemiluminescence.

Sigma Chemie GmbH, Deisenhofen, Germany: zymosan A from Saccharomyces cerevisiae yeast; 4-methylumbelliferyl-Nacetyl- $\beta$ - $D$-glucosaminide; 4 -methylumbelliferone; $4 \beta$-phorbol $12 \beta$-myristate $13 \alpha$-acetate; $N$-formyl- $L$-methionyl- $L$-leucyl- $L$ phenylalanine; lipopolysaccharide from Escherichia coli serotype No. 055:B5, phenol extract; xanthine oxidase, grade I from buttermilk, 0.47 units $/ \mathrm{mg}$ protein, $16.7 \mathrm{kU} / \mathrm{l}$, protein $38 \mathrm{~g} / \mathrm{l}$.

Blood bank, Medizinische Hochschule Hannover, Germany: venous blood from male donors anticoagulated with $31.3 \mathrm{~g} / \mathrm{l}$ sodium citrate solution ( $9 \mathrm{vol}$ of blood $+1 \mathrm{vol}$ of citrate solution); pool plasma was obtained after centrifugation at $1500 \mathrm{~g}$ and room temperature for 10 minutes.

Fluka, Switzerland: Nonidet P40 (ethylphenylpolyethyleneglycol, NP40).
Fenwal, Division of Travenol Laboratories, Inc. Deerfield, IL, USA: nylon fiber from Leuko-Pak Leukocyte Filter, Code 4C 2401.

Fresenius, Bad Homburg, Germany: sodium citrate solution $31.3 \mathrm{~g} / \mathrm{l}$.

Serva, Heidelberg, Germany: latex, Unisphere latex 22, 0.777 $\mu \mathrm{m}$ diameter, $10 \%$.

Riedel-de Haen, Seelze-Hannover, Germany: hypoxanthine.

\section{Chemiluminescence of neutrophils}

Neutrophils were isolated from citrated blood as previously described (7). Briefly, for the chemiluminescence response the chemiluminescence vials contained the following solutions (volumes of blanks in brackets): $485 \mu \mathrm{l}(505 \mu \mathrm{l})$ Minimal Essential Medium, $10 \mu \mathrm{l}(10 \mu \mathrm{l})$ luminol (final concentration $0.4 \mathrm{mmol} / \mathrm{l}$ ), $20 \mu \mathrm{l}(20 \mu \mathrm{l})$ pool plasma, $10 \mu \mathrm{l}(10 \mu \mathrm{l})$ ascorbic acid (final concentration $0-6 \mathrm{mmol} / \mathrm{l}), 20 \mu \mathrm{l}(0 \mu \mathrm{l})$ stimulant (final concentration $\mathrm{N}$-formyl- $L$-methionyl- $L$-leucyl- $L$-phenylalanine 3.5 $\mu \mathrm{mol} / \mathrm{l}$, latex $1.75 \mathrm{ml} / \mathrm{l}$, lipopolysaccharide $7 \mu \mathrm{g} / \mathrm{l}$, zymosan $\mathrm{A}$ $3.5 \mathrm{~g} / \mathrm{l}, 4 \beta$-phorbol $12 \beta$-myristate $13 \alpha$-acetate $5 \mu \mathrm{mol} / \mathrm{l})$, and $25 \mu \mathrm{l}(25 \mu \mathrm{l})$ neutrophil suspension in Minimal Essential Medium with 25000 cells.

For chemiluminescence measurements of blood the reaction mixtures were composed as follows: $500 \mu \mathrm{l}(510 \mu \mathrm{l})$ Minimal Essential Medium, $10 \mu \mathrm{l}(10 \mu \mathrm{l})$ luminol (final concentration 0.4 $\mathrm{mmol} / \mathrm{l}), 10 \mu \mathrm{l}(10 \mu \mathrm{l})$ ascorbic acid (final concentration $0-6$ $\mathrm{mmol} / \mathrm{l}), 10 \mu \mathrm{l}(0 \mu \mathrm{l}) 4 \beta$-phorbol $12 \beta$-myristate $13 \alpha$-acetate (final concentration $5 \mu \mathrm{mol} / \mathrm{l}$ ) or zymosan (final concentration 3.5 $\mathrm{g} / \mathrm{l})$, and $40 \mu \mathrm{l}(40 \mu \mathrm{l})$ citrated blood.

Neutrophils were counted in a Neubauer haemocytometer after staining with Türk's solution.

Replicates and blanks were started simultaneously in a six channel biolumat LB 9505 (Berthold, Wildbad, Germany), the photon emission was recorded continuously for 60 minutes, the peak maximum values of the blanks were subtracted from the stimulation values and the photon emission was referred to 25000 cells (chemiluminescence measurement of isolated neutrophils) and to 200000 cells (chemiluminescence measurement of citrated blood), respectively.

\section{Enzyme release from neutrophils}

The enzyme release was measured as follows. Isolated neutrophils were suspended in Minimal Essential Medium at about $4 \cdot 10^{9} / 1$; the reaction mixtures contained: $520 \mu \mathrm{l}(520 \mu \mathrm{l})$ neutrophil suspension, $0 \mu \mathrm{l}(20 \mu \mathrm{l})$ Minimal Essential Medium, $20 \mu \mathrm{l}(20 \mu \mathrm{l})$ pool plasma, $10 \mu \mathrm{l}(10 \mu \mathrm{l})$ ascorbic acid (final concentration $0-6 \mathrm{mmol} / \mathrm{l})$, and $20 \mu \mathrm{l}(0 \mu \mathrm{l})$ stimulant (final concentration as described in the section 'Chemiluminescence of neutrophils'). Immediately after starting by the addition of the stimulant, a $100 \mu \mathrm{l}$ aliquot of the reaction mixture was removed and added to $100 \mu$ ldigitonin/Nonidet P40 to lyse the neutrophils for the determination of the total content of elastase $^{1}$ ) and $\beta-N$-acetylglucosaminidase ${ }^{1}$ ) (7). After 45 minutes at $37^{\circ} \mathrm{C}$ the remaining reaction mixture was centrifuged at $12000 \mathrm{~g}$ and room temperature for 1 minute. The supernatant was removed and analysed for $\beta-\mathrm{N}$-acetylglucosaminidase spectrofluorimetrically (7) and for elastase by the IMAC test. The percentage of enzyme released was calculated.

Nylon fibre adherence and chemiluminescence of neutrophils

For the determination of the nylon fibre adherence and adherence-induced and lucigenin-enhanced chemiluminescence response a modification of the previously described test procedure 
(8) was used: replicates of $100 \mu \mathrm{l}(100 \mu \mathrm{l})$ citrated blood, 450 $\mu \mathrm{l}(450 \mu \mathrm{l})$ Minimal Essential Medium, $10 \mu \mathrm{l}(10 \mu \mathrm{l})$ lucigenin (final concentration $0.23 \mathrm{mmol} / \mathrm{l}), 10 \mu \mathrm{l}(10 \mu \mathrm{l})$ ascorbic acid (final concentration $0-6 \mathrm{mmol} / \mathrm{l}$ ) were incubated for $30 \mathrm{~min}$ utes at $37^{\circ} \mathrm{C}$ with (A) and without (B) $5 \mathrm{mg}$ of nylon fibre. The photon emission was recorded during incubation. Then the nylon fibre was removed, neutrophils (PMNL) were counted in A and B using a haemocytometer after staining with Türk's solution, the adherence was calculated by the formula

$$
\text { Adherence }=\frac{\mathrm{PMNL} / \mathrm{l}_{\mathrm{B}}-\mathrm{PMNL} / \mathrm{l}_{\mathrm{A}}}{\mathrm{PMNL} / \mathrm{l}_{\mathrm{b}}}
$$

and the photon emission (peak maximum) was referred to only adhered cells after subtractive correction for the blank.

Chemiluminescence of the hypoxanthine/xanthine oxidase system

To $470 \mu$ l phosphate buffer $(100 \mathrm{mmol} / \mathrm{l}, \mathrm{pH} 7.4)$ with ethylenediaminetetraacetate $(1 \mathrm{mmol} / \mathrm{l})$ and luminol $(0.23 \mathrm{mmol} / \mathrm{l})$ were added $10 \mu \mathrm{l}$ hypoxanthine (final concentration 0.2 $\mathrm{mmol} / \mathrm{l}), 10 \mu \mathrm{l}$ ascorbic acid (final concentration $0-1 \mathrm{mmol} / \mathrm{l}$ ) and $10 \mu \mathrm{l}$ xanthine oxidase (final concentration $0.68 \mathrm{U} / \mathrm{l}$ ). The photon emission was recorded for 1 minute, and the peak maximum values were determined for each ascorbic acid concentration.

\section{Statistics}

The data are expressed as mean \pm SEM. Statistical comparisons were performed by Student's t-test for paired data and Wilcoxon's matched pairs signed rank test, respectively. The null hypothesis was rejected for $\mathrm{p}<0.05$.

\section{Results}

Figure 1 exhibits the chemiluminescence response of isolated neutrophils activated by different stimuli in the absence and presence of different concentrations of ascorbic acid. Despite the very different absolute amounts of oxygen radicals produced by these stimuli (fig. 1a) there was a comparable dose-dependent reduction of the chemiluminescence response beginning at $0.6 \mathrm{mmol} / \mathrm{l}$ ascorbic acid for all stimuli (fig. $1 \mathrm{~b}$ ).

There was no dose-dependent inhibition of the $\beta-\mathrm{N}$ acetylglucosaminidase (fig. 2). and elastase (fig. 3) release from isolated neutrophils after stimulation with $\quad \mathrm{N}$-formyl- $L$-methionyl- $L$-leucyl- $L$-phenylalanine, latex, lipopolysaccharide, zymosan and $4 \beta$-phorbol $12 \beta$-myristate $13 \alpha$-acetate. On the contrary, a slight dose-dependent increase of $\beta$ - $\mathrm{N}$-acetylglucosaminidase was observed after stimulation with zymosan or $4 \beta$-phorbol $12 \beta$-myristate $13 \alpha$-acetate (fig. 2 ) and of elastase after stimulation with $4 \beta$-phorbol $12 \beta$ myristate $13 \alpha$-acetate (fig. 3 ).

The chemiluminescence response of blood was inhibited dose-dependently by ascorbic acid after stimulation with $4 \beta$-phorbol $12 \beta$-myristate $13 \alpha$-acetate (fig. 4) or zymosan (fig. 5).
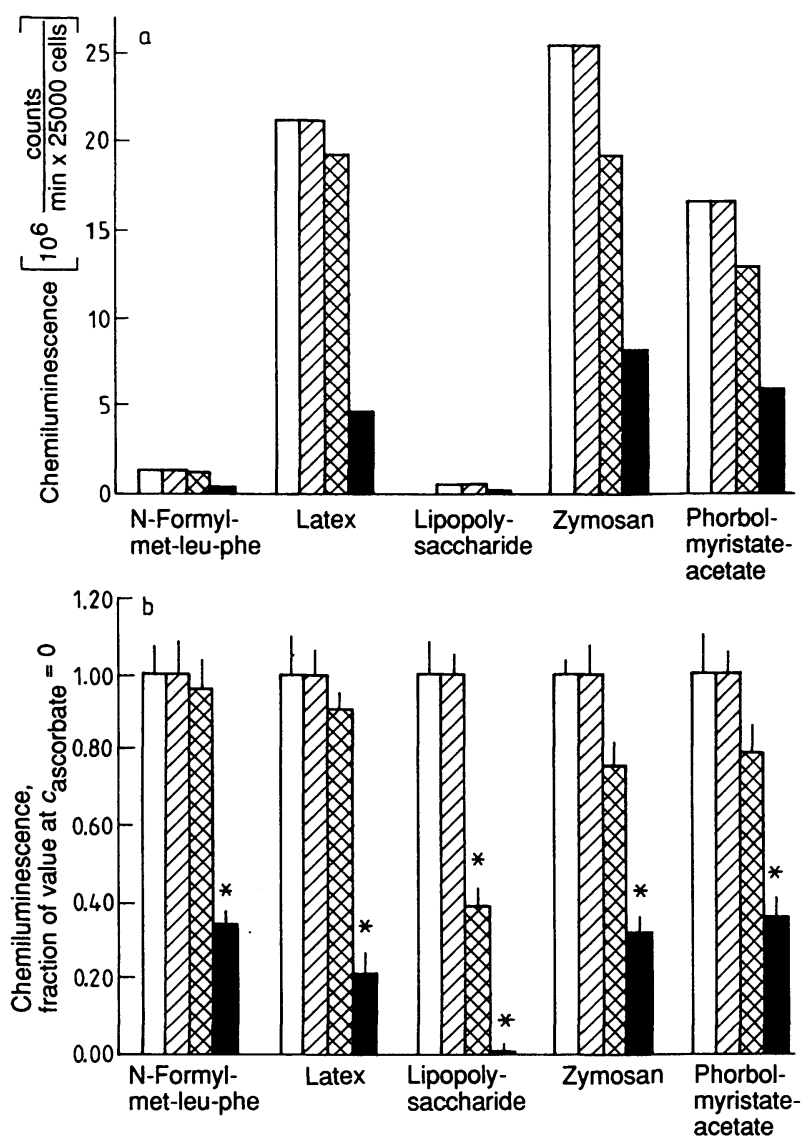

Fig. 1. Chemiluminescence response of isolated human neutrophils stimulated with $\mathrm{N}$-formyl- $L$-methionyl- $L$-leucyl- $L$ phenylalanine, latex, lipopolysaccharide from Escherichia coli, zymosan $\mathrm{A}$ and $4 \beta$-phorbol $12 \beta$-myristate $13 \alpha$-acetate in the absence and presence of different ascorbic acid concentrations

$(\square 0 \mathrm{mmol} / \mathrm{l} \quad \square .06 \mathrm{mmol} / \mathrm{l} 0.6 \mathrm{mmol} / \mathrm{l} \quad 6.0$ $\mathrm{mmol} / \mathrm{l})$

a data calculated as $10^{6}$ counts/min per 25000 polymorphonuclear leukocytes $(\overline{\mathrm{x}} ; \mathrm{n}=3$ )

$\mathrm{b}$ data referred to $0 \mathrm{mmol} / \mathrm{l}$ ascorbic acid $(\overline{\mathrm{x}} \pm \mathrm{SEM}$; $\mathrm{n}=3$ )

* $\mathrm{p}<0.05$ data vs $0 \mathrm{mmol} / \mathrm{l}$ data

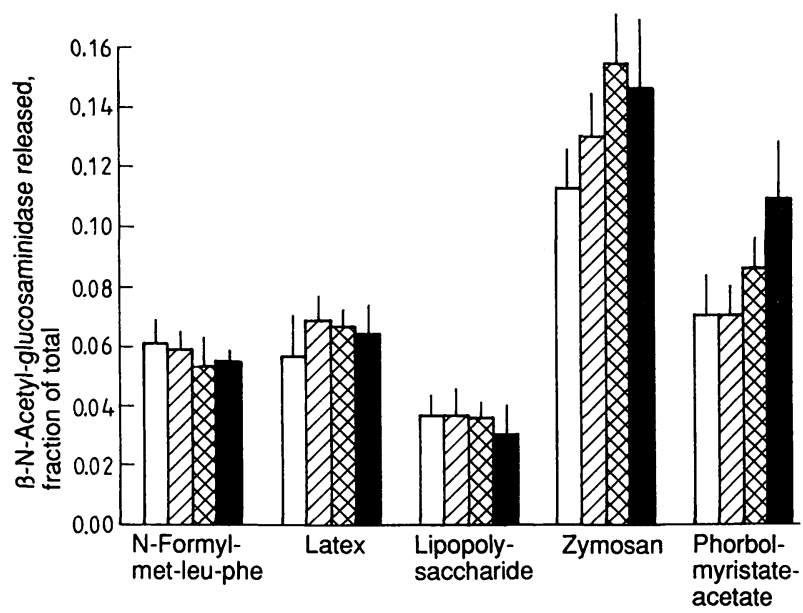

Fig. 2. $\beta$-N-Acetylglucosaminidase release from isolated human neutrophils ( $\overline{\mathrm{x}} \pm \mathrm{SEM} ; \mathrm{n}=3)$ stimulated with the stimuli described in figure 1 in the absence and presence of different ascorbic acid concentrations

(口 $0 \mathrm{mmol} / \mathrm{l} \quad \square 0.06 \mathrm{mmol} / \mathrm{l} \quad 0.6 \mathrm{mmol} / \mathrm{l} \quad 6.0$ $\mathrm{mmol} / \mathrm{l})$ 


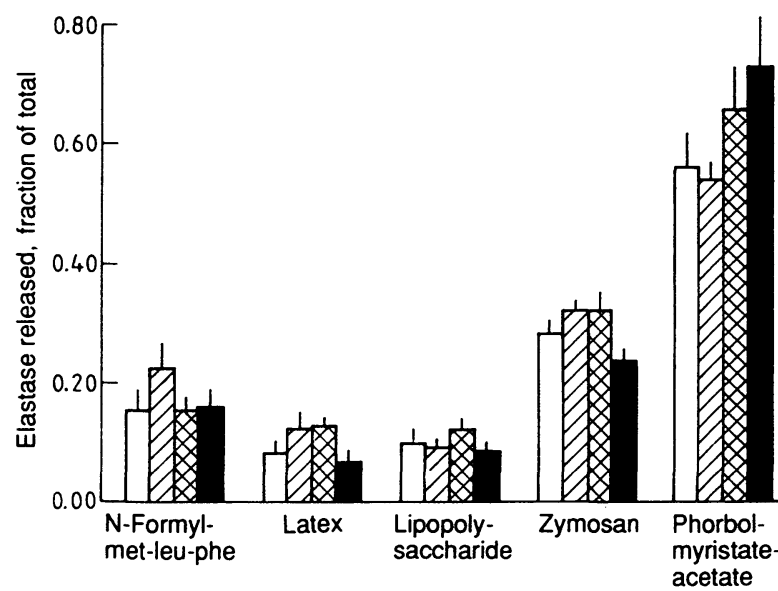

Fig. 3. Elastase release from isolated human neutrophils $(\bar{x} \pm$ SEM,$n=3)$ stimulated with the stimuli described in figure 1 in the absence and presence of different ascorbic acid concentrations ( $0 \mathrm{mmol} / \mathrm{l} \quad 0.06 \mathrm{mmol} / \mathrm{l} \otimes 0.6 \mathrm{mmol} / \mathrm{l} \quad 6.0$ $\mathrm{mmol} / \mathrm{l})$

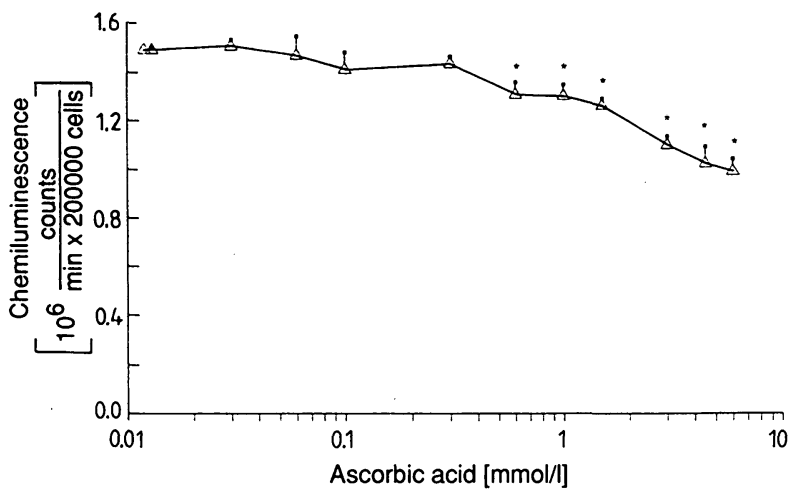

Fig. 4. Chemiluminescence response of blood $(\bar{x} \pm S E M$, $\mathrm{n}=5$ ) exposed to $5 \mu \mathrm{mol} / 14 \beta$-phorbol $12 \beta$-myristate $13 \alpha$-acetate in dependency on the ascorbic acid concentration

* $\mathrm{p}<0.05$ data vs $0.012 \mathrm{mmol} / \mathrm{l}$ data

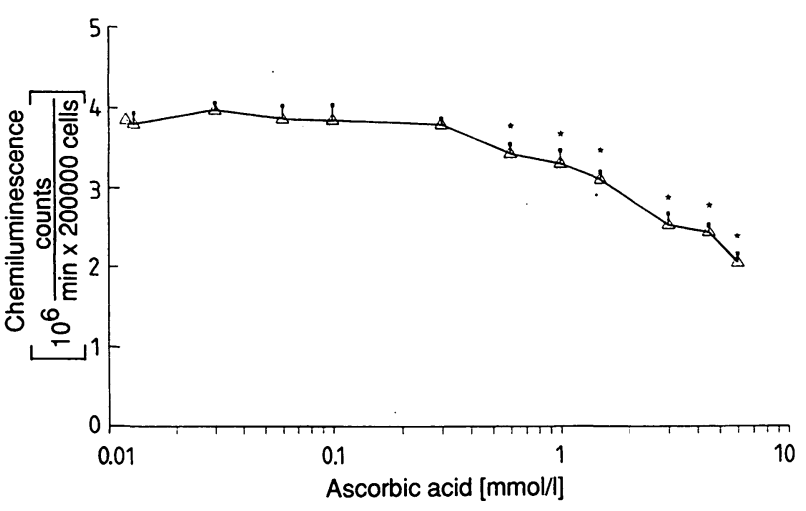

Fig. 5. Chemiluminescence response of blood ( $\bar{x} \pm S E M$; $\mathrm{n}=6$ ) exposed to $3.5 \mathrm{~g} / \mathrm{l}$ zymosan in dependency on the ascorbic acid concentration

* $\mathrm{p}<0.05$ data vs $0.012 \mathrm{mmol} / \mathrm{l}$ data

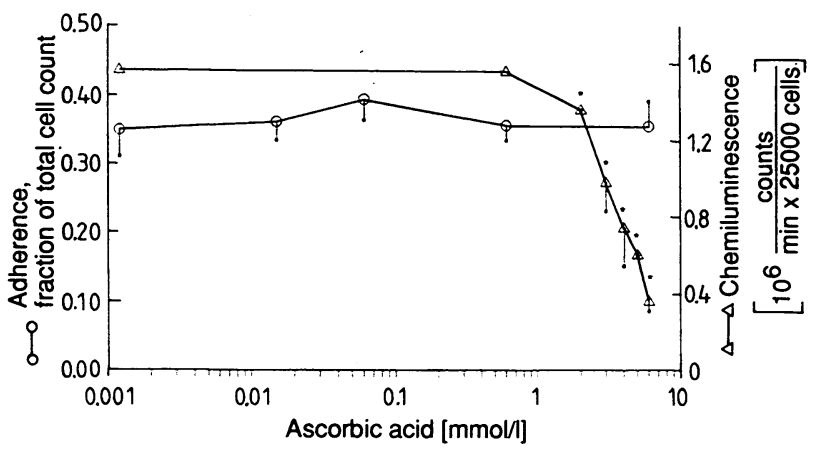

Fig. 6. Adherence and chemiluminescence response $\left(10^{6}\right.$ counts min per 25000 polymorphonuclear leukocytes) by the interaction of blood and nylon fibre $(\bar{x} \pm S E M ; n=4)$ in dependency on the ascorbic acid concentration * $\mathrm{p}<0.05$ data vs $0.0012 \mathrm{mmol} / \mathrm{l}$ data

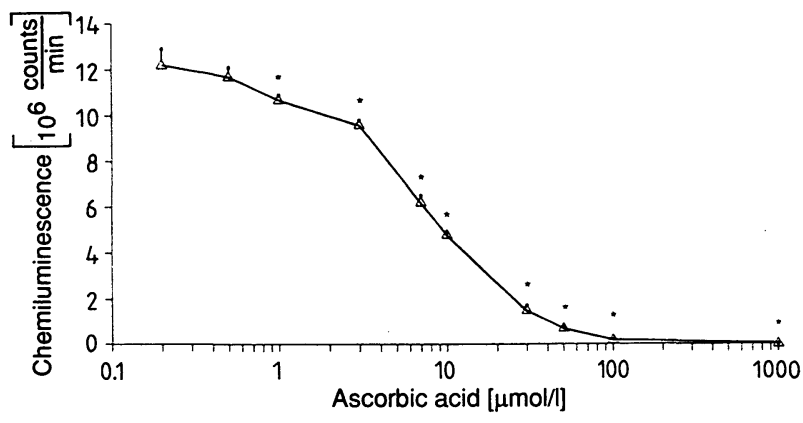

Fig. 7. Inhibition of the hypoxanthine $(0.2 \mathrm{mmol} / \mathrm{l}) / \mathrm{xanthine}$ oxidase $(0.68 \mathrm{U} / \mathrm{l})$-generated oxygen radicals in dependency on the ascorbic acid concentration $(\bar{x} \pm S E M$; $\mathrm{n}=3$ )

* $\mathrm{p}<0.05$ data vs $0.2 \mu \mathrm{mol} / \mathrm{l}$ data

During adherence of neutrophils to nylon fibre, ascorbic acid reduced the chemiluminescence response in a dose-dependent manner, whereas there was no concomitant alteration of the adherence (fig. 6).

Hypoxanthine/xanthine oxidase-generated oxygen radicals showed photon emission curves which were totally suppressed by ascorbic acid. The dose-dependency demonstrated a complete radical scavenging at ascorbic acid concentrations greater than $100 \mu \mathrm{mol} / 1$ (fig. 7).

\section{Discussion}

Studies by many laboratories have shown a protective effect of different antioxidants against ischemia/reperfusion injury and organ failure. In this report the dose-dependent effect of ascorbic acid has been shown to scavenge oxygen radicals produced by both systems involved in such tissue damage processes:

(i) the activated neutrophil, and 
(ii) the hypoxanthine/xanthine oxidase system of e.g. endothelial cells.

The oxygen radical production of the latter system was completely inhibited by small concentrations of ascorbic acid, whereas the incomplete scavenging of respiratory burst-generated oxygen radicals of neutrophils varied in dependence on the stimulus, and higher doses of ascorbic acid were required. This may be a result of the intracellularly produced portion of oxygen radicals which is normally inaccessible for the extracellular ascorbic acid. But one could conceivably increase the intracellular ascorbic acid concentration by insulin, since ascorbic acid/dehydroascorbic acid and glucose seem to use an identical transport system in human neutrophils (10). Concerning further neutrophil functions, our data demonstrated that the adherence of neutrophils to nylon fibre was not influenced, even by high concentrations of ascorbic acid that produced a nearly complete reduction of the simultaneously observed oxygen radical production. Also the release of lysosomal enzymes was generally unaffected by ascorbic acid, but there was a slight dose-dependent increase of the $\beta-\mathrm{N}$-acetylglucosaminidase release when zymosan or $4 \beta$-phorbol $12 \beta$-myr- istate $12 \alpha$-acetate was used for activation, and of the elastase release when $4 \beta$-phorbol $12 \beta$-myristate $13 \alpha$ acetate was used for activation. We cannot explain this observation.

In view of its excellent antioxidative properties which are highly important for several biochemical pathways $(6,11)$ and its non-toxic character, ascorbic acid should primarily be recommended as a supplement in animal experiments and clinical studies in patients with trauma, shock and sepsis, i.e. it should be used in the same as other antioxidants like $\mathrm{N}$-acetylcysteine (12). Furthermore, ascorbic acid can also be recommended for trials to prevent or to reduce reperfusion injuries.

In preliminary experiments we found that sheep tolerated high doses of ascorbic acid intravenously $(1 \mathrm{~g} / \mathrm{kg} \mathrm{b}$. w. as a bolus injection followed by a continuous infusion of $0.2 \mathrm{~g} / \mathrm{kg} \cdot \mathrm{h}$ for 5 hours produced a 50 fold increase of the normal plasma concentration). Experiments are currently being performed in our laboratory on the use of ascorbic acid to prevent the endotoxin-induced pulmonary dysfunction in the sheep model according to Staub et al. (13).

\section{References}

1. Brigham, K. L. (1990) Oxidant stress and adult respiratory distress syndrome. Eur. Respir. J. 3 (Suppl. 11), 482s - 484s.

2. Sussman, M. S. \& Bulkley, G. B. (1990) Oxygen-derived free radicals in reperfusion injury. Methods in Enzymology $186,711-723$.

3. Schlag, G. \& Redl, H. (1990) Startreaktionen des posttraumatischen Schocks - Reperfusionsschaden. Hefte zur Unfallheilkunde 212, 53-60.

4. Anderson, R. (1991) Assessment of the roles of vitamin C, vitamin $E$, and beta-carotene in the modulation of oxidant stress mediated by cigarette smoke-activated phagocytes. Am. J. Clin. Nutr. 53 (1. suppl.), 358s-361s.

5. Frei, B., Stocker, R., England, L. \& Ames, B. N. (1990) Ascorbate: the most effective antioxidant in human blood plasma. In: Antioxidants in therapy and preventive medicine (Emerit, I., ed.) pp. 155-163, Plenum Press, New York.

6. Friedrich, W. (1987) Handbuch der Vitamine, pp. 596-639, Urban \& Schwarzenberg, München - Wien-Baltimore.

7. Dwenger, A., Schweitzer, G. \& Regel, G. (1986) Bronchoalveolar lavage fluid and plasma proteins, chemiluminescence response and protein contents of polymorphonuclear leukocytes from blood and lavage fluid in traumatized patients. J. Clin. Chem. Clin. Biochem. 24, 73-88.

8. Dwenger, A., Schweitzer, G., Röllig, G. \& Nerlich, M. L. (1990) Dose-dependent inhibition by prostaglandin E1 of oxygen radical production, adherence and enzyme release of stimulated polymorphonuclear leukocytes. Fresenius J. Anal. Chem. 337, 88-89.

9. Dwenger, A., Regel, G., Schweitzer, G., Röllig, G. \& Lindena, J. (1991) Nonspecific immune system, plasma proteins and characteristics of the erythrocyte insulin receptor. In: Adult respiratory distress syndrome - an aspect of multiple organ failure (Sturm, J. A., ed.) pp. $91-127$, Springer-Verlag, Berlin-Heidelberg.

10. Bigley, R., Wirth, M., Layman, D., Riddle, M. \& Stankova, L. (1983) Interaction between glucose and dehydroascorbate transport in human neutrophils and fibroblasts. Diabetes $32,545-548$.

11. Kolb, E. (1990) Einige neuere Erkenntnisse zum Stoffwechsel und zur Funktion der Ascorbinsäure. Z. Gesamte Inn. Med. 45, 205-210.

12. Bernard, G. R. (1990) Potential of N-acetylcysteine as treatment for the adult respiratory distress syndrome. Eur. Respir. J. 3 (Suppl. 11), 496s - 498s.

13. Staub, N. C., Bland, R. D., Brigham, K. L., Demling, R. H., Erdmann, A. J. \& Woolverton, W. C. (1975) Preparation of chronic lung lymph fistulas in sheep. J. Surg. Res. $19,315-320$.

Dr. rer. nat. Alexander Dwenger Abteilung für Klinische Biochemie Medizinische Hochschule Hannover Konstanty-Gutschow-Straße 8

W-3000 Hannover 61

Bundesrepublik Deutschland 
